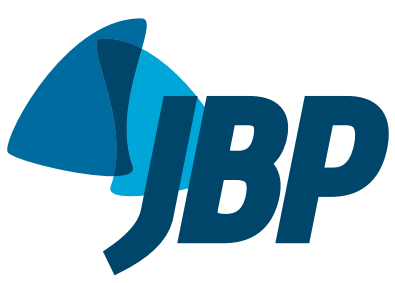

1. Hospital da Previdência, Instituto de Previdência dos Servidores do Estado de Minas Gerais - IPSEMG Belo Horizonte (MG) Brasil.

2. Departamento de Pediatria, Faculdade de Medicina, Universidade Federal de Minas Gerais, Belo Horizonte (MG) Brasil.

Submitted: 28 August 2016.

Accepted: 26 February 2017

Study carried out in the Departamento de Pediatria da Faculdade de Medicina da Universidade Federal de Minas Gerais Belo Horizonte (MG) Brasil.

\section{Parapneumonic pleural effusion: early versus late thoracoscopy}

\author{
Rodrigo Romualdo Pereira1', Cristina Gonçalves Alvim²,
} Cláudia Ribeiro de Andrade $^{2}$, Cássio da Cunha Ibiapina ${ }^{2}$

\begin{abstract}
Objective: To evaluate the best time to perform thoracoscopy for the treatment of complicated parapneumonic pleural effusion in the fibrinopurulent phase in patients $\leq$ 14 years of age, regarding the postoperative evolution and occurrence of complications. Methods: This was a retrospective comparative study involving patients with parapneumonic pleural effusion presenting with septations or loculations on chest ultrasound who underwent thoracoscopy between January of 2000 and January of 2013. The patients were divided into two groups: early thoracoscopy (ET), performed by day 5 of hospitalization; and late thoracoscopy (LT), performed after day 5 of hospitalization. Results: We included 60 patients, 30 in each group. The mean age was 3.4 years; 28 patients $(46.7 \%)$ were male; and $47(78.3 \%)$ underwent primary thoracoscopy (no previous simple drainage). The two groups were similar regarding gender, age, weight, and type of thoracoscopy ( $p>0.05$ for all). There was a significant difference between the ET and the LT groups regarding the length of the hospital stay (14.5 days vs. 21.7 days; $p<0.001)$. There were also significant differences between the groups regarding the duration of fever in days; the total number of days from admission to the initiation of drainage; and the total number of days with the drain in place. Eight patients (13.6\%) had at least one post-thoracoscopy complication, there being no difference between the groups. There were no deaths. Conclusions: Performing ET by day 5 of hospitalization was associated with shorter hospital stays, shorter duration of drainage, and shorter duration of fever, although not with a higher frequency of complications, requiring ICU admission, or requiring blood transfusion.
\end{abstract}

Keywords: Empyema, pleural; Thoracoscopy; Pneumonia.

\section{INTRODUCTION}

It is estimated that between $28 \%$ and $53 \%$ of children hospitalized with bacterial pneumonia have complications such as pleural effusion or empyema. ${ }^{(1)}$ Although there has been a reduction in the frequency of hospitalizations for pneumonia, especially in countries where there is universal vaccination for Streptococcus pneumonia, the incidence of parapneumonic pleural effusion (PPE) has increased and appears to be related to the emergence of antibiotic-resistant strains. ${ }^{(1,2)}$

The critical factor in the prognosis of PPE is the time from the onset of the condition to the initiation of adequate treatment. ${ }^{(1,2)}$ Until the early 1990s, surgical debridement via thoracoscopy was indicated after a period of simple drainage, if there was no clinical improvement. ${ }^{(3)}$ Currently, there is evidence from retrospective studies, ${ }^{(4-17)}$ prospective studies, ${ }^{(18-20)}$ systematic reviews, ${ }^{(21-25)}$ and a meta-analysis(26) in favor of the superiority of thoracoscopy over simple drainage in the treatment of pleural empyema, indicating that thoracoscopy should be performed, especially when ultrasound shows septations or loculations. (27) However, PPE being approached late is still common, there being delay and difficulty in referring such children to referral centers.
Early referral for thoracoscopy has the advantage of the procedure being easy to perform, allowing better drainage, less perioperative bleeding, shorter surgical time, shorter duration of chest drain in place, and a greater likelihood of obtaining full expansion of the affected lung, avoiding thoracotomy for pulmonary decortication. ${ }^{(5,8,18)}$ In addition, early thoracoscopy (ET) allows a shorter length of hospital stay (LOS), shorter duration of fever, and reduced risk of complications of prolonged drainage (pain, bronchopleural fistula, lung entrapment, and nosocomial infection). ${ }^{(1,26)}$

This study is motivated by the need to evaluate the optimal timing of thoracoscopy, as well as the postprocedure course and complications. The objective was to compare ET vs. late thoracoscopy (LT) as an approach for complicated PPE in the fibrinopurulent phase.

\section{METHODS}

This was a retrospective comparative study involving analysis of the medical charts of children diagnosed with complicated PPE in the fibrinopurulent phase who were admitted to a pediatric referral hospital. The study project was approved by the Research Ethics Committee of the Federal University of Minas Gerais (Ruling no. 353.069). 
Being retrospective, this study was granted a waiver of written informed consent.

The course of complicated PPE involves three phases: exudative; fibrinopurulent; and organizing. In the exudative phase, which occurs within $72 \mathrm{~h}$ after the development of the initial effusion, simple chest drainage is usually sufficient. However, in the fibrinopurulent phase, which occurs within 3 to 14 days after the development of the initial effusion, we have to resort to the use of fibrinolytic agents or to mechanical debridement via thoracoscopy for correct cleaning of the various loculations in the pleural cavity.

We included all children admitted to the inpatient unit with a diagnosis of complicated PPE who presented with septations, debris, or loculations on chest ultrasound and who underwent thoracoscopy between January of 2000 and January of 2013. Indications for thoracoscopy were persistent fever or respiratory symptoms (clinical criteria) and loculations (ultrasound criteria). In all cases, the fibrinopurulent phase was confirmed during surgery. We excluded patients with complicated PPE who, at the time of the first evaluation by pediatric surgery, were found to be in the organizing phase, underwent pulmonary decortication via thoracotomy, or presented with necrotizing pneumonia on chest CT. We also excluded patients who were transferred to another hospital after the procedure.

Between 2000 and 2004, thoracoscopy was performed using a mediastinoscope (Carlens' technique) under general anesthesia without selective intubation, with patients in a lateral decubitus position, lying on the nonaffected side. The mediastinoscope was inserted into the thoracic cavity through a small incision in the 4th intercostal space at the midaxillary line, and the other instruments (vacuum pump and clamp forceps) were inserted through the mediastinoscope. A 22-gauge chest drain was inserted into the pleural cavity after the mediastinoscope was removed. Between 2004 and 2013, thoracoscopy was performed as a video-assisted procedure under general anesthesia without selective intubation, with patients in a lateral decubitus position, lying on the nonaffected side. A small incision was made in the 4th intercostal space at the midaxillary line, through which a 5- or 10-mm trocar was inserted and $\mathrm{a} 30^{\circ}$ endoscope was passed. Subsequently, carbon dioxide insufflation at a pressure of $6 \mathrm{mmHg}$ created an artificial pneumothorax and partially collapsed the lung, and a 5-mm trocar was inserted in the same intercostal space at the posterior axillary line, through which instruments (vacuum pump, forceps, and the endoscope itself) could be handled. Septations and fibrin clots were removed, and the thoracic cavity was flushed with saline. At the end of the procedure, a 22-gauge chest drain was put in place through the first trocar incision. The mean procedure time was 40 min, and all patients underwent chest drainage at the end of the procedure. Whenever possible, pleural fluid was collected and sent for bacteriological examination.

For the purpose of comparison, the patients were divided into two treatment groups: ET, performed by day 5 of hospitalization; and LT, performed after day 5 of hospitalization.

Secondary thoracoscopy was defined as surgical debridement after simple drainage. Primary thoracoscopy (no previous simple drainage) was performed when there were ultrasound indications for it (septations, debris, or loculations).

The intervening variables analyzed were age, weight, gender, duration of fever before admission, undergoing thoracentesis before thoracoscopy, undergoing simple drainage before thoracoscopy, requiring ICU admission, requiring blood transfusion, undergoing chest $\mathrm{CT}$, and occurrence of complications.

In order to assess patient course in the ET and the LT groups, the response variables were LOS; LOS after thoracoscopy; duration of fever in days; duration of fever in days, after admission; total number of days from admission to the initiation of drainage; total number of days with the drain in place; and total number of days with the drain in place after thoracoscopy.

Data were analyzed with the Statistical Package for the Social Sciences, version 14.0 (SPSS Inc., Chicago, IL, USA). Associations between treatment group (ET and LT) and each of the variables of interest were assessed with the chi-square test and Student's t-test, assuming non-equality of variances. The level of significance was set at $5 \%(p<0.05)$.

\section{RESULTS}

We analyzed the medical charts of 65 children, of whom 2 were excluded because they were transferred to another hospital after the surgical procedure and 3 were excluded because they underwent thoracotomy for decortication or presented with necrotizing pneumonia in the first evaluation by surgery. The final sample therefore consisted of 60 patients. The mean age was 3.4 years, and $28(46.7 \%)$ were male. Most (83\%) resided in the city of Belo Horizonte, Brazil.

Chest ultrasound revealed septations, debris, or loculations in all patients, 42 (70.2\%) of whom presented with these changes on the first ultrasound. Chest CT was performed in only 3 patients (5.0\%), of whom 1 was in the ET group and 2 were in the LT group ( $p=0.576)$.

The mean time from hospital admission to thoracoscopy was 6.4 days (2.9 and 9.8 days, respectively, in the ET and the LT groups). The mean time from hospital admission to the first chest drainage was 5 days (range: $0-17$ days). In the ET group, the time from fever onset to thoracoscopy was less than 15 days in all patients. In the LT group, the time from fever onset to thoracoscopy was greater than 21 days in only 1 patient. Therefore, 59 patients (98.3\%) underwent thoracoscopy within the first three weeks of the fever course.

Of the sample as a whole, 47 patients (78.3\%) underwent thoracoscopy as the primary intervention (no previous simple drainage). Pleuroscopy was 
performed in 19 patients (31.7\%), and video-assisted thoracoscopic surgery was performed in 41 (68.3\%). The ET and the LT groups each had 30 patients. Table 1 shows the patient descriptive characteristics and the procedures performed before thoracoscopy, by treatment group and total.

The ET and the LT groups were similar $(p>0.05)$ regarding male/female proportion, mean age, mean weight, and type of thoracoscopy. The proportion of patients undergoing thoracentesis and the proportion of patients undergoing simple drainage were higher in the LT group, with a trend toward a statistically significant difference in the latter proportion ( $p=0.057)$. The patients in the ET group showed longer duration of fever before hospital admission ( $p<0.001)$.

Table 2 presents data regarding patient course by treatment group and total. There were statistically significant differences between the ET and the LT groups $(p<0.05)$ regarding the mean LOS, the duration of fever in days, the total number of days from admission to resolution of fever, the total number of days from admission to the initiation of drainage, and the total number of days with the drain in place. With regard to the LOS after thoracoscopy and the total number of days with the drain in place after thoracoscopy, the two groups were similar, with no statistically significant differences being found. Of the sample as a whole, 47 patients $(78.3 \%)$ were admitted to the ICU after surgical debridement. The proportion of patients who required ICU care was similar in the ET and the LT groups (76.7\% and $80.0 \%$, respectively; $p=0.754$ ). When taking into account only the patients admitted to the ICU, there was no difference in the length of ICU stay between the ET and the LT groups (4.6 vs. 7.7 days; $p=0.310)$.

Eight patients (13.6\%) had at least one complication after thoracoscopy: bronchopleural fistula, in $4(6.8 \%)$; lung entrapment, in 2 (3.4\%); fistula and entrapment, in $1(1.7 \%)$; and pneumothorax, in $1(1.7 \%)$; there being no significant difference between the groups ( $p$ $=0.959$ ). There were no deaths among the patients included in the study. One patient in the LT group required thoracotomy for decortication. Overall, 21 patients (35\%) required blood transfusion at some point during hospitalization. This proportion was higher in the LT group ( $n=13 ; 43.3 \%$ ) than in the ET group ( $n$ $=8 ; 26.7 \%)$, but there was no statistically significant difference $(p=0.176)$.

\section{DISCUSSION}

Various studies have shown that, when approaching pleural empyema, surgical debridement via thoracoscopy is a safe, effective procedure that allows a shorter LOS compared with simple drainage. $(1,23,25,26)$ However, few studies have compared timing of thoracoscopy (ET vs. LT) in children, as has been done in the present study. ${ }^{(4-9)}$

ET, performed by day 5 of hospitalization, was associated with a better course, characterized by a

Table 1. Patient descriptive and comparative statistics regarding gender, age, weight, type of thoracoscopy, and procedures before thoracoscopy, by treatment group and total.

\begin{tabular}{|c|c|c|c|c|}
\hline \multirow[t]{2}{*}{ Variable } & \multicolumn{3}{|c|}{ Treatment } & \multirow[t]{2}{*}{$\mathbf{p}$} \\
\hline & $\begin{array}{c}\text { Early } \\
(\mathrm{n}=30)\end{array}$ & $\begin{array}{c}\text { Late } \\
(\mathrm{n}=30)\end{array}$ & $\begin{array}{c}\text { Total } \\
(N=60)\end{array}$ & \\
\hline \multicolumn{5}{|l|}{ Gender, n (\%) } \\
\hline Male & $11(36.7)$ & $17(56.7)$ & $28(46.7)$ & \multirow[t]{2}{*}{0.121} \\
\hline Female & $19(63.3)$ & $13(43.3)$ & $32(53.3)$ & \\
\hline \multicolumn{5}{|l|}{ Age, years } \\
\hline Median (min-max) & $3.0(0.0-8.0)$ & $3.0(0.0-14.0)$ & $3.0(0.0-14.0)$ & \multirow[t]{2}{*}{0.983} \\
\hline Mean \pm SD & $3.4 \pm 2.2$ & $3.4 \pm 2.7$ & $3.4 \pm 2.5$ & \\
\hline \multicolumn{5}{|l|}{ Weight, $\mathrm{kg}^{\mathrm{a}}$} \\
\hline Median (min-max) & $14.75(10.50-34.00)$ & $15.00(7.50-52.00)$ & $15.00(7.50-52.00)$ & \multirow[t]{2}{*}{0.972} \\
\hline Mean \pm SD & $17.06 \pm 5.79$ & $17.13 \pm 8.46$ & $17.10 \pm 7.11$ & \\
\hline \multicolumn{5}{|l|}{ Fever before admission, days ${ }^{b}$} \\
\hline Median (min-max) & $5.5(0.0-9.0)$ & $3.0(0.0-7.0)$ & $4.0(0.0-9.0)$ & \multirow[t]{2}{*}{$<0.001$} \\
\hline Mean \pm SD & $5.6 \pm 2.6$ & $3.2 \pm 2.1$ & $4.4 \pm 2.6$ & \\
\hline \multicolumn{5}{|l|}{ Type of thoracoscopy, n (\%) } \\
\hline Pleuroscopy & $8(26.7)$ & $11(36.7)$ & $19(31.7)$ & \multirow[t]{2}{*}{0.405} \\
\hline Video-assisted thoracoscopic surgery & $22(73.3)$ & $19(63.3)$ & $41(68.3)$ & \\
\hline \multicolumn{5}{|l|}{ Thoracentesis, n (\%) } \\
\hline Yes & $15(50)$ & $21(70)$ & $36(60)$ & \multirow[t]{2}{*}{0.114} \\
\hline No & $15(50)$ & $9(30)$ & $24(30)$ & \\
\hline \multicolumn{5}{|l|}{ Simple drainage before thoracoscopy, $n$ (\%) } \\
\hline Yes & $3(10)$ & $10(33)$ & $13(22)$ & \multirow[t]{2}{*}{0.057} \\
\hline No & $27(90)$ & $20(67)$ & $47(78)$ & \\
\hline
\end{tabular}

min: minimum; and max: maximum. a Data regarding 27 patients in the late treatment group. ${ }^{b}$ Data regarding 28 patients in the early treatment group and 26 patients in the late treatment group. 
Table 2. Patient descriptive and comparative statistics regarding patient course, by treatment group and total.

\begin{tabular}{|c|c|c|c|c|}
\hline \multirow[t]{2}{*}{ Variable } & \multicolumn{3}{|c|}{ Treatment } & \multirow[t]{2}{*}{ p } \\
\hline & $\begin{array}{c}\text { Early } \\
(n=30)\end{array}$ & $\begin{array}{c}\text { Late } \\
(n=30)\end{array}$ & $\begin{array}{c}\text { Total } \\
(\mathbf{N}=60)\end{array}$ & \\
\hline \multicolumn{5}{|l|}{ Length of hospital stay, days ${ }^{a}$} \\
\hline Median (min-max) & $13.0(7.0-42.0)$ & $19.5(11.0-49.0)$ & $16.0(7.0-49.0)$ & $<0.001$ \\
\hline Mean \pm SD & $14.5 \pm 6.5$ & $21.7 \pm 8.2$ & $18.1 \pm 8.2$ & \\
\hline \multicolumn{5}{|c|}{ Length of hospital stay after thoracoscopy, days } \\
\hline Median (min-max) & $10.0(7.0-39.0)$ & $10.0(4.0-30.0)$ & $11.8(4.0-39.0)$ & 0.885 \\
\hline Mean \pm SD & $11.7 \pm 6.3$ & $11.9 \pm 6.2$ & $10.0 \pm 6.2$ & \\
\hline Fever, days ${ }^{\mathrm{b}}$ & 21 & 22 & 43 & \\
\hline Median (min-max) & $11.0(3.0-27.0)$ & $17.0(10.0-40.0)$ & $14.0(3.0-40.0)$ & 0.014 \\
\hline Mean \pm SD & $12.8 \pm 5.9$ & $17.6 \pm 6.2$ & $15.1 \pm 6.4$ & \\
\hline \multicolumn{5}{|c|}{ Time from admission to resolution of fever, days ${ }^{c}$} \\
\hline Median (min-max) & $7.0(0.0-23.0)$ & $13.0(7.0-41.0)$ & $10.5(0.0-41.0)$ & 0.001 \\
\hline Mean \pm SD & $7.8 \pm 5.9$ & $15.6 \pm 7.8$ & $11.7 \pm 7.9$ & \\
\hline \multicolumn{5}{|c|}{ Time from admission to the initiation of drainage, days ${ }^{\mathrm{a}}$} \\
\hline Median (min-max) & $3.0(-5.0$ a 7.0$)$ & $7.0(0.0-17.0)$ & $5.0(-5.0$ a 17.0$)$ & $<0.001$ \\
\hline Mean \pm SD & $2.6 \pm 2.3$ & $7.4 \pm 3.9$ & $5.0 \pm 4.0$ & \\
\hline \multicolumn{5}{|l|}{ Duration of drain in place, days ${ }^{d}$} \\
\hline Median (min-max) & $3.0(2.0-10.0)$ & $3.5(2.0-27.0)$ & $3.0(2.0-7.0)$ & 0.027 \\
\hline Mean \pm SD & $3.6 \pm 2.4$ & $7.4 \pm 6.6$ & $5.5 \pm 5.3$ & \\
\hline \multicolumn{5}{|c|}{ Duration of drain in place after thoracoscopy, days ${ }^{d}$} \\
\hline Median (min-max) & $3.0(0.0-8.0)$ & $3.0(0.0-18.0)$ & $3.0(0.0-18.0)$ & 0.330 \\
\hline Mean \pm SD & $3.3 \pm 2.0$ & $4.3 \pm 4.2$ & $3.8 \pm 3.3$ & \\
\hline
\end{tabular}

min: minimum; and max: maximum. a Data regarding 29 patients in the early treatment group. ${ }^{\mathrm{b}}$ Data regarding 21 patients in the early treatment group and 22 patients in the late treatment group. 'Data regarding 21 patients in each of the two treatment groups. ${ }^{\mathrm{D}}$ Data regarding 19 patients in the early treatment group and 20 patients in the late treatment group.

shorter LOS, shorter duration of drainage, and shorter duration of fever, and was not associated with a higher frequency of complications, requiring ICU admission, or requiring blood transfusion. The fact that the ET and the LT groups were similar regarding age, gender, and weight and were in the same stage of the effusion (fibrinopurulent phase, as determined on the basis of chest ultrasound findings and duration of fever) improves the reliability of our results. It should be noted that the LOS after thoracoscopy and the duration of drainage after thoracoscopy were similar in the two groups, suggesting that the timing of thoracoscopy was a determinant of patient course.

Chest ultrasound performed with quality equipment by professionals experienced in evaluating children in $100 \%$ of the patients provided the basis for a thoracoscopy approach, since there is evidence of the ineffectiveness of a conservative approach in cases of pleural effusion with septations and loculations. (27) CT was rarely required, which is in line with other studies and with the concern over the use of procedures involving radiation, especially in children. (27)

The longer duration of fever before admission in the patients in the ET group could be the explanation for the decision to pursue earlier surgical intervention. It is of interest to observe that, despite the longer duration of fever before admission, the patients in this group had a better course, underscoring the importance of
ET. However, since the present study was retrospective, other factors that were not analyzed, such as clinical severity, time from admission to surgical evaluation, and the surgeon's decision regarding the initial approach, may have influenced the decision regarding the timing of the surgical intervention. At the hospital where the study was conducted, there is a protocol recommending that chest ultrasound should be performed in all cases of PPE and that thoracoscopy should be performed in cases with septations and loculations. However, the team is composed of seven surgeons, and this may have introduced a bias. The decision regarding the timing of thoracoscopy was made at the discretion of the surgeon, there being variations in the decision regarding optimal timing within the team. Nevertheless, patient course after thoracoscopy was the same in the two groups, suggesting that treatment responses and, probably, the quality of the surgical technique were similar.

Simple drainage was performed in the two groups (in $10 \%$ and $33 \%$ of the patients in the ET and the LT groups, respectively). The proportion of patients undergoing simple drainage was higher in the LT group, with a trend toward a statistically significant difference $(p=0.057)$. Some authors have shown that primary thoracoscopy is superior to secondary thoracoscopy (performed after simple drainage). ${ }^{(7-9)}$ However, it is known that some cases may respond well to conservative treatment (with or without 
simple drainage) and that it is not easy, a priori, to distinguish between such cases and those that will require thoracoscopy. ${ }^{27,28)}$ What this study intended to show is that thoracoscopy should not be delayed, even if other procedures are performed.

The LOS is the main variable analyzed in order to assess the courses of patients undergoing thoracoscopy for complicated PPE because it is a reliable datum, even for retrospective analysis, and reflects several other aspects of the patients' courses. The mean LOS has been reported to range from 5.8 to 21 days. $(4-11,13-20,29,30)$

There are studies that report the LOS, the duration of chest drainage, the success rate, and the frequency of complications, but with no comparison group regarding the timing of thoracoscopy. ${ }^{(13-17,29,30)}$

Other authors have compared primary thoracoscopy or ET with other approaches for the treatment of PPE. (10,11,18-20) The superiority of thoracoscopy over conservative treatment, with or without simple drainage, is well established. Avansino et al.(26) showed in a meta-analysis that the surgical intervention rate is ten times higher in patients undergoing simple drainage than in those undergoing primary thoracoscopy. Shah et al. ${ }^{(11)}$ found that, in addition to a longer LOS, the simple drainage group had a higher cost of hospitalization attributable to medication use and tests performed. Recent prospective studies have shown that there is a similarity between fibrinolytic drainage and the thoracoscopic approach, the cost being lower and the frequency of therapeutic failure being higher for the former. $^{(19,20)}$

Three studies have compared primary with secondary thoracoscopy, and four, including the present study, have compared timing of thoracoscopy (ET vS. LT; Chart 1). In all of them, the results showed a shorter LOS for ET and/or primary thoracoscopy (range: 10.1-14.5 days). ${ }^{(4-9)}$

Regardless of being comparative or not, some studies have shown surprising results, reporting mean LOS rates of less than 10 days. Analysis of these studies shows that it is possible that not all patients were in the fibrinopurulent phase, there being some very early referrals for thoracoscopy, which was performed within

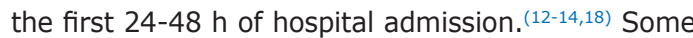
of those patients could have benefited simply from a simple drainage (exudative phase).

One difficulty in comparing results is the criteria for patient selection. Shah et al.(11) excluded children younger than 1 year, and, in most studies, not all patients underwent an ultrasound evaluation. The mean age in our study was lower than that reported in some other studies, ${ }^{(8-10)}$ which may have affected the LOS. The inclusion of patients with PPE who did not undergo an ultrasound evaluation, along with very early referral for thoracoscopy, may mean excessive referral for thoracoscopy and explain the shorter LOS observed in some studies.

In addition, there are differences in access to health care and in the organization of health care systems, all of which can affect the response variable "LOS". For example, in the study by Bishay et al., ${ }^{(14)}$ addressing primary thoracoscopy and primary thoracotomy, the mean duration of preoperative symptoms was 10 days, and other interventions (thoracentesis, simple drainage, and fibrinolytic drainage) were performed at the secondary referral center, before admission to

Chart 1. Thoracoscopy as an approach for pleural effusion in pediatric patients, 2004-2013. Studies comparing timing of thoracoscopy (early vs. late or primary vs. secondary).

\begin{tabular}{|c|c|c|c|c|c|c|c|c|}
\hline Authors & Design & $\begin{array}{l}\text { Age, } \\
\text { years }^{\text {a }}\end{array}$ & $\begin{array}{c}\text { Participants, } \\
\text { n }\end{array}$ & $\begin{array}{c}\text { Type of } \\
\text { thoracoscopy }\end{array}$ & $\begin{array}{l}\text { LOS, } \\
\text { days }^{\text {b }}\end{array}$ & $\begin{array}{c}\text { Post- } \\
\text { surgery } \\
\text { LOS, days }\end{array}$ & $\begin{array}{c}\text { Drain, } \\
\text { days }\end{array}$ & $\begin{array}{c}\text { Complications, } \\
\%\end{array}$ \\
\hline \multirow{2}{*}{$\begin{array}{l}\text { Kalfa } \\
\text { et al. }{ }^{(5)}\end{array}$} & \multirow{2}{*}{$P$} & 4.00 & 26 & Early $(\leq 4 \mathrm{~d})$ & $10.9 \pm 4.3$ & \multirow{2}{*}{ NR } & 4.5 & 3.8 \\
\hline & & $(0.42-16.00)$ & 24 & Late & $17.0 \pm 8.4$ & & 8.0 & 29.0 \\
\hline \multirow{2}{*}{$\begin{array}{l}\text { Kalfa } \\
\text { et al. }{ }^{(4)}\end{array}$} & \multirow{2}{*}{$\mathrm{R}$} & \multirow{2}{*}{$\begin{array}{c}4.00 \\
(0.83-15.00)\end{array}$} & 10 & Early $(\leq 4 \mathrm{~d})$ & $\begin{array}{c}11.8 \\
(5-23)\end{array}$ & \multirow{2}{*}{ NR } & 5.3 & 0 \\
\hline & & & 10 & Late & $\begin{array}{c}19.9 \\
(6-40)\end{array}$ & & 9.4 & 30 \\
\hline \multirow{2}{*}{$\begin{array}{l}\text { Schultz } \\
\text { et al. }{ }^{(6)}\end{array}$} & \multirow{2}{*}{$\mathrm{R}$} & 4 & 49 & Early $(\leq 48$ h) & $11.5 \pm 6.6$ & \multirow{2}{*}{ NR } & \multirow{2}{*}{ NS } & \multirow{2}{*}{ NR } \\
\hline & & $(0-17)$ & 76 & Late & $15.2 \pm 8.6$ & & & \\
\hline \multirow{2}{*}{$\begin{array}{l}\text { Meier } \\
\text { et al. }{ }^{(7)}\end{array}$} & \multirow{2}{*}{$\mathrm{R}$} & \multirow{2}{*}{$<18$} & 107 & Primary & 10.1 & \multirow{2}{*}{ NR } & \multirow{2}{*}{ NR } & \multirow{2}{*}{13.8} \\
\hline & & & 44 & Secondary & 14.3 & & & \\
\hline \multirow{2}{*}{$\begin{array}{l}\text { Schneider } \\
\text { et al. }{ }^{(8)}\end{array}$} & \multirow{2}{*}{$\mathrm{R}$} & \multirow{2}{*}{$<17$} & 31 & Primary & 10.5 & 7.4 & 4.2 & \multirow{2}{*}{ NR } \\
\hline & & & 18 & Secondary & 15.0 & 10.3 & 7.7 & \\
\hline \multirow{2}{*}{$\begin{array}{l}\text { Aziz } \\
\text { et al. }{ }^{(9)}\end{array}$} & \multirow{2}{*}{$\mathrm{R}$} & \multirow{2}{*}{$\begin{aligned} & 5.8^{c} \\
< & 18.0\end{aligned}$} & 13 & Primary & 11 & \multirow{2}{*}{ NR } & \multirow{2}{*}{ NR } & \multirow{2}{*}{ NR } \\
\hline & & & 15 & Secondary & 18 & & & \\
\hline \multirow{2}{*}{$\begin{array}{l}\text { Present } \\
\text { study }\end{array}$} & \multirow{2}{*}{$\mathrm{R}$} & \multirow{2}{*}{$\begin{array}{c}3.4 \\
(0.6-14.0)\end{array}$} & 30 & Early $(\leq 5 \mathrm{~d})$ & $14.5 \pm 6.5$ & 11.7 & 3.6 & 13.3 \\
\hline & & & 30 & Late & $21.7 \pm 8.2$ & 11.9 & 7.4 & 13.8 \\
\hline
\end{tabular}

LOS: length of hospital stay; P: prospective; d: days; R: retrospective; Primary: thoracoscopy as the first therapeutic intervention; Secondary: thoracoscopy after simple drainage; NR: not reported; and NS: not significant. ${ }^{a}$ Values expressed as median (interquartile range) or as age bracket. 'Values expressed as mean ( \pm SD) or as median (interquartile range). 'Value expressed as mean. 
the tertiary center where the study was conducted. The LOS at the referral hospital was not included in the calculation of LOS.

It is also possible that the presence of comorbidities, the clinical severity of pneumonia, the virulence of the etiologic agents, and the criteria for hospital admission and discharge (either more or less conservative) are different among the various studies and that these variables, which were not analyzed, also affect the LOS.

The frequencies of therapeutic failure and complications were low (3.3\% and $13.3 \%$, respectively) and similar to those reported in the literature when thoracoscopy is performed in the fibrinopurulent phase, before the organizing phase. The occurrence of complications can explain the longer LOS in some cases. ${ }^{(17,30)}$ The frequency of therapeutic failure was lower than that reported in a study that did not exclude patients with empyema in the organizing phase or with necrotizing pneumonia, two factors that are known to be related to a higher occurrence of complications and a longer LOS. ${ }^{(16)}$

ICU admission occurred after thoracoscopy in most cases, it being indicated because of perioperative respiratory instability and because of the need for careful postoperative monitoring, in addition to the ICU bed availability at the hospital where the study was conducted. Such care may have been a contributing factor to the favorable courses experienced by the patients. The present study's limitations are mainly due to the fact that it was retrospective, which is common to most studies on this topic because of the small number of annual cases at each facility. In order to minimize the bias of retrospective data collection, we analyzed different course-related variables, and the results were consistent.

Another limitation to extrapolating the results obtained in the present study is due to the need for training of pediatric surgeons in thoracoscopy and the need for a structure of care, given that the procedures have significant morbidity (13.3\%). The Department of Pediatric Surgery of the hospital where the study was conducted is a referral center in the city of Belo Horizonte, Brazil, and its surgeons are trained in thoracoscopy, as are the anesthesiologists and the pediatric intensive care team. This unfortunately is not the reality in many hospitals providing pediatric care in Brazil, and multiple drainage attempts are still common in cases of loculated and septated effusion, which prolongs hospitalization.

We conclude that there should be early referral for thoracoscopy, within the first 5 days of hospital admission, for surgical debridement of PPE in the fibrinopurulent phase (with septations or loculations). Reducing the LOS in children benefits not only the children themselves, minimizing their physical and emotional suffering, but also their families and the population as a whole, because it allows a reduction in costs and the release of hospital beds. Prospective studies, comparison with the initial fibrinolytic approach, and evaluation of the costs of the different approaches in Brazil should be the object of future study.

\section{REFERENCES}

1. Islam S, Calkins CM, Goldin AB, Chen C, Downard CD, Huang EY, et al. The diagnosis and management of empyema in children: a comprehensive review from the APSA Outcomes and Clinical Trials Committee. J. Pediatr. Surg. 2012;47(11):2101-10. https://doi. org/10.1016/j.jpedsurg.2012.07.047

2. Janahi IA, Fakhoury K. Management and prognosis of parapneumonic effusion and empyema in children. In: Rose BD, editor. UpToDate. Waltham, MA: UpToDate; 2013.

3. Fraga JC, Lima A, Schopf L, Antunes C. Thoracoscopy with mediastinoscope in pediatric complicated parapneumonic effusion [Article in Portuguese]. J Pediatr (Rio J). 1999;75(6):470-6. https://doi. org/10.2223/JPED.364

4. Kalfa N, Allal H, Montes-Tapia F, Lopez M, Forgues D, Guibal MP et al. Ideal timing of thoracoscopic decortication and drainage for empyema in children. Surg Endosc. 2004;18(3):472-7. https://doi. org/10.1007/s00464-002-9206-6

5. Kalfa N, Allal H, Lopez M, Saguintaah M, Guibal MP, Sabatier-Laval E, et al. Thoracoscopy in pediatric pleural empyema: a prospective study of prognostic factors. J Pediatr Surg. 2006;41(10):1732-7. https://doi.org/10.1016/j.jpedsurg.2006.05.066

6. Schultz KD, Fan LL, Pinsky J, Ochoa L, Smith EO, Kaplan SL, et al. The changing face of pleural empyemas in children: epidemiology and management. Pediatrics. 2004;113(6):1735-40. https://doi. org/10.1542/peds.113.6.1735

7. Meier AH, Hess CB, Cilley RE. Complications and treatment failures of video-assisted thoracoscopic debridement for pediatric empyema. Pediatr Surg Int. 2010;26(4):367-71. https://doi.org/10.1007/s00383010-2562-0

8. Schneider CR, Gauderer MW, Blackhurst D, Chandler JC, Abrams RS. Video-assisted thoracoscopic surgery as a primary intervention in pediatric parapneumonic effusion and empyema. Am Surg. 2010;76(9):957-61

9. Aziz A, Healey JM, Qureshi F, Kane TD, Kurland G, Green M, et al.
Comparative analysis of chest tube thoracostomy and video-assisted thoracoscopic surgery in empyema and parapneumonic effusion associated with pneumonia in children. Surg Infect (Larchmt). 2008;9(3):317-23. https://doi.org/10.1089/sur.2007.025

10. Li ST, Gates RL. Primary operative management for pediatric empyema: decreases in hospital length of stay and charges in a national sample. Arch Pediatr Adolesc Med. 2008;162(1):44-8. https://doi.org/10.1001/archpediatrics.2007.10

11. Shah SS, Ten Have TR, Metlay JP. Costs of treating children with complicated pneumonia: a comparison of primary video-assisted thoracoscopic surgery and chest tube placement. Pediatr Pulmonol. 2010;45(1):71-7. https://doi.org/10.1002/ppul.21143

12. Shah SS, DiCristina CM, Bell LM, Ten Have T, Metlay JP. Primary early thoracoscopy and reduction in length of hospital stay and additional procedures among children with complicated pneumonia: results of a multicenter retrospective cohort study. Arch Pediatr Adolesc Med. 2008;162(7):675-81. https://doi.org/10.1001/archpedi.162.7.675

13. Velaiutham S, Pathmanathan S, Whitehead B, Kumar R. Videoassisted thoracoscopic surgery of childhood empyema: early referral improves outcome. Pediatr Surg Int. 2010;26(10):1031-5. https://doi. org/10.1007/s00383-010-2663-9

14. Bishay M, Short M, Shah K, Nagraj S, Arul S, Parikh D, et al. Efficacy of video-assisted thoracoscopic surgery in managing childhood empyema: a large single-centre study. J Pediatr Surg. 2009;44(2):33742. https://doi.org/10.1016/j.jpedsurg.2008.10.083

15. Pappalardo $E$, Laungani A, Demarche $M$, Erpicum $P$. Early thoracoscopy for the management of empyema in children. Acta Chir Belg. 2009;109(5):602-5. https://doi.org/10.1080/00015458.200 9.11680495

16. Chen JS, Huang KC, Chen YC, Hsu HH, Kuo SW, Huang PM, et al. Pediatric empyema: Outcome analysis of thoracoscopic management. J Thorac Cardiovasc Surg. 2009;137(5):1195-9. https:// doi.org/10.1016/j.jtcvs.2008.10.031 
17. Freitas S, Fraga JC, Canani F. Thoracoscopy in children with complicated parapneumonic pleural effusion at the fibrinopurulent stage: a multi-institutional study. J Bras Pneumol. 2009;35(7):660-8. https://doi.org/10.1590/S1806-37132009000700007

18. Kurt BA, Winterhalter KM, Connors RH, Betz BW, Winters JW Therapy of parapneumonic effusions in children: video-assisted thoracoscopic surgery versus conventional thoracostomy drainage. Pediatrics. 2006;118(3):e547-53. https://doi.org/10.1542/peds.2005 2719

19. St Peter SD, Tsao K, Spilde TL, Keckler SJ, Harrison C, Jackson MA, et al. Thoracoscopic decortication vs tube thoracostomy with fibrinolysis for empyema in children: a prospective, randomized trial. J. Pediatr. Surg. 2009;44(1):106-11; discussion 111. https://doi. org/10.1016/j.jpedsurg.2008.10.018

20. Sonnappa S, Cohen G, Owens CM, Van Doorn C, Cairns J, Stanojevic $\mathrm{S}$, et al. Comparison of urokinase and video-assisted thoracoscopic surgery for treatment of childhood empyema. Am J Respir Crit Care Med. 2006;174(2):221-7. https://doi.org/10.1164/rccm.2006010270C

21. Gates RL, Caniano DA, Hayes JR, Arca MJ. Does VATS provide optimal treatment of empyema in children? A systematic review. J Pediatr Surg. 2004;39(3):381-6. https://doi.org/10.1016/j. jpedsurg.2003.11.045

22. Balfour-Lynn IM, Abrahamson E, Cohen G, Hartley J, King S, Parikh $D$, et al. BTS guidelines for the management of pleural infection in children. Thorax. 2005;60 Suppl 1:i1-21. https://doi.org/10.1136/ thx.2004.030676

23. Coote N, Kay ES. WITHDRAWN: Surgical versus non-surgical management of pleural empyema. Cochrane Database Syst Rev. 2009;(4):CD001956.

24. Kokoska ER, Chen MK; New Technology Committee. Position paper on video-assisted thoracoscopic surgery as treatment of pediatric empyema. J Pediatr Surg. 2009;44(1):289-93. https://doi. org/10.1016/j.jpedsurg.2008.08.037

25. Scarci M, Zahid I, Billé A, Routledge T. Is video-assisted thoracoscopic surgery the best treatment for paediatric pleural empyema? Interact Cardiovasc Thorac Surg. 2011;13(1):70-6. https://doi.org/10.1510/ icvts.2010.254698

26. Avansino JR, Goldman B, Sawin RS, Flum DR. Primary operative versus nonoperative therapy for pediatric empyema: a meta-analysis. Pediatrics. 2005;115(6):1652-9. https://doi.org/10.1542/peds.20041405

27. Calder A, Owens CM. Imaging of parapneumonic pleural effusions and empyema in children. Pediatr Radiol. 2009;39(6):527-37. https:// doi.org/10.1007/s00247-008-1133-1

28. Carter E, Waldhausen J, Zhang W Hoffman L, Redding G. Management of children with empyema: Pleural drainage is not always necessary. Pediatr Pulmonol. 2010;45(5):475-80. https://doi. org/10.1002/ppul.21200

29. Knudtson J, Grewal H. Pediatric empyema-an algorithm for early thoracoscopic intervention. JSLS. 2004:8:31-4

30. Kang DW, Campos JR, Andrade Filho Lde O, Engel FC, Xavier AM, Macedo $\mathrm{M}$, et al. Thoracoscopy in the treatment of pleural empyema in pediatric patients. J Bras Pneumol. 2008;34(4):205-11. https://doi. org/10.1590/S1806-37132008000400004 